\section{(2) OPEN ACCESS}

\title{
Visual outcomes after cataract surgery among the elderly residents in the 'homes for the aged' in South India: the Hyderabad Ocular Morbidity in Elderly Study
}

\author{
Srinivas Marmamula (D) , 1,2,3,4,5 Navya Rekha Barrenakala, ${ }^{1}$ Rajesh Challa, ${ }^{1}$ \\ Thirupathi Reddy Kumbham, ${ }^{1}$ Satya Brahmanandam Modepalli, ${ }^{1}$ \\ Ratnakar Yellapragada, ${ }^{1}$ Madhuri Bhakki, ${ }^{1}$ Jagadesh C Reddy (D) , ${ }^{6}$ David S Friedman, ${ }^{5}$ \\ Rohit C Khanna (D) 1,4
}

For numbered affiliations see end of article.

\section{Correspondence to Dr Srinivas Marmamula, Gullapalli Pratibha Rao International Centre for Advancement of Rural Eye care, L V Prasad Eye Institute, Hyderabad 500034, India; sri.marmamula@lvpei.org}

DSF and RCK contributed equally

Received 8 June 2020 Accepted 23 July 2020 Revised 8 July 2020
Check for updates

(c) Author(s) (or their employer(s)) 2020. Re-use permitted under CC BY. Published by BMJ.

To cite: Marmamula $\mathrm{S}$, Barrenakala NR, Challa R, et al. Br J Ophthalmol Epub ahead of print: [please include Day Month Year]. doi:10.1136/bjophthalmol2020-317167

\section{ABSTRACT \\ Background/Aim To report visual outcomes and factors associated with good visual outcomes after cataract surgery among the elderly residents in 'homes for the aged' in Hyderabad, India. \\ Methods Individuals aged $\geq 60$ years were recruited from 41 'homes for the aged'. All participants had a detailed eye examinations including visual acuity (VA) assessment, refraction, slit-lamp examination and fundus imaging by trained professionals. A detailed history of cataract surgery was recorded. Multivariate logistic regression was used to determine the factors associated with good visual outcomes after cataract surgery which was defined as presenting VA of $6 / 18$ or better in the operated eye. Visual impairment (VI) is defined as presenting VA worse than $6 / 18$ in the operated eye.}

Results 1215 eyes of 703 individuals had cataract surgery. The mean age of these participants was 77.5 years (SD: 8.2 years; range: $60-108$ years), $66.8 \%$ were women, $29.9 \%$ reported diabetes and $61 \%$ reported hypertension. 406/1215 (33.4\%; 95\% Cl 30.8 to 36.1) eyes had VI after cataract surgery. Posterior capsular opacification (31.8\%; $n=129)$ was the leading cause of VI followed by uncorrected refractive error (24.1\%; $n=98)$. The prevalence of good outcomes was $66.6 \%$ (95\% Cl 63.8 to 69.2 ). On applying multivariable analysis, younger age, self-reported hypertension, independent mobility, surgery in a non-government (as opposed to private) hospital and undergoing paid surgery were associated with good outcomes.

Conclusions One-third of the eyes of elderly individuals living in homes for the aged that had previously undergone cataract surgery had VI. Regular eye examinations with the provision of laser capsulotomy and appropriate refractive correction can substantially improve their vision.

Cataract is the leading cause of visual impairment (VI) worldwide, affecting 65.2 million people. ${ }^{1}$ Cataract surgery is a cost-effective, safe and predictable procedure, ${ }^{2}$ which improves quality of life and visual function. ${ }^{3-5}$ Yet, millions suffer from vision loss due to cataract, and some who are operated have poor vision due to issues with the quality of eye surgery or pre-existing eye conditions. ${ }^{6-10}$ In India, nearly $30 \%$ of operated eyes remain vision impaired due to uncorrected refractive errors (UREs), posterior segment diseases and surgical complications. ${ }^{6-9}$ The Andhra Pradesh Eye Disease Study (APEDS) found that $50 \%$ of the operated eyes had VI in Hyderabad, India, in the year 1999. ${ }^{11}$ However, studies conducted later in the states of Telangana and Andhra Pradesh reported better outcomes, with less than 30\% having VI after cataract surgery. ${ }^{78}$ These and many other studies of cataract outcomes were population-based ${ }^{6811}$; no studies have been on visual outcomes in individuals living in residential care in India.

One important effect of urbanisation and societal change in India is the increasing number of 'homes for the aged', especially in urban and semiurban locations. The Hyderabad Ocular Morbidity in Elderly Study (HOMES) was undertaken to understand the eye health situation of the elderly in residential care in Hyderabad, India. ${ }^{12}$ We previously reported a large burden of avoidable vision loss and UREs in this population. ${ }^{13}{ }^{14}$ In this paper, we report on the visual outcomes of cataract surgery in a large cohort of residents living in these homes in South India.

\section{MATERIALS AND METHODS}

The study protocol was approved by the Institutional Review Board of the Hyderabad Eye Research Foundation, L V Prasad Eye Institute, Hyderabad, India, and was carried out following the Declaration of Helsinki. All participants provided written informed consent. The HOMES protocol has been published. ${ }^{12}$

The participating homes for the aged facilities have been described in our previous publications. ${ }^{12-14}$ Briefly, homes for the aged are a recent phenomenon in India and hence not a wellorganised sector. The homes are diverse both in terms of scope, amenities provided and the number of elderly living in them and are typically run by non-governmental (NGO), religious or voluntary organisations with support from the government and philanthropists (free and subsidised homes). In private homes, either the elderly person or their kin pay the user fee. Some private homes have nursing staff to attend to medical needs and other support staff to assist elderly residents in their routine tasks. ${ }^{12-14}$ 
In HOMES, a total of 46/76 (60.5\%) homes for the aged who agreed to participate in the study (including 5 for pilot study) were included. ${ }^{13}{ }^{14}$ A total of 16/76 (21.1\%) homes were not interested in participation in the study. The residents who were aged $\geq 60$ years at the time of enumeration and residing in these homes for at least 1 month and agreed to participate were included in the study. All the residents in the selected homes were enumerated, and all those who were available and provided consent were examined. A total of 1512 elderly residents were enumerated, of which 1182 participants (78.1\%) were examined. Those examined and not examined were similar in terms of gender $(p=0.31)$; however, the mean age of these examined was slightly higher $(75.0$ years vs 74.2 years; $p=0.05) .{ }^{13} 14$

Detailed personal and demographic information, systemic and ocular history were collected. The ocular history included information on previous eye examinations, current and past use of spectacles as well as medical and surgical history. If a participant reported having undergone cataract surgery, details of the cataract surgery were recorded such as the place of surgery (government hospital which typically provides free surgeries), private hospital (provides paying surgeries only) or NGO-run hospital (provides both paying and non-paying surgeries, as is done in LV Prasad Eye Institute), cost of surgery (free or paid) and time since surgery. If any surgical reports were available for the participants, they were reviewed, and details were documented. Systemic history included self-report of hypertension or diabetes. Apart from this, mobility status based on the interviewer's observations and self-report was classified as 'independently mobile', 'mobile with assistance' or 'immobile/bedridden'.

All participants underwent a comprehensive eye examination as described previously. ${ }^{12}$ In brief, monocular distance visual acuity (VA) was assessed using a logMAR (minimum angle of resolution) chart at a distance of $3 \mathrm{~m}$ under ambient lighting conditions. Refraction was done and the best-corrected VA was recorded. Slit-lamp examination was conducted using a portable slit lamp, and intraocular pressure was measured using a Perkins handheld tonometer. Fundus images of the disc and macula were captured using a non-mydriatic fundus camera (Visuscout 100 Handheld Fundus Camera, Carl Zeiss Meditec, Dublin, CA, USA). Among those with aphakia or pseudophakia, a slit-lamp examination and distance direct ophthalmoscopy were done in a semidark room to grade density, area and the extent of posterior capsular opacification (PCO) in the pupillary area. This was graded as (a) no posterior capsule, (b) clear posterior capsule (clear red glow), (c) hazy posterior capsule (dull red glow), (d) opaque posterior capsule (no red glow visible) and (e) cannot examine the posterior capsule (for reasons such as the opaque cornea, absent globe, phthisis bulbi). ${ }^{12} 13$

\section{Definitions}

Good visual outcome was defined as presenting VA of 6/18 or better in the operated eye (definition 1 ). We also analysed visual outcomes using presenting VA of $6 / 12$ or better in the operated eye to define a good visual outcome (definition 2). Among those who had bilateral cataract surgery, VA in the better-seeing eye was used to define VI and good outcome. The revised Indian categories of VI, which now include a definition for severe VI, were used, and these included moderate VI (VA worse than 6/18-6/ 60 ), severe VI (VA worse than 6/60-3/60), and blindness (VA worse than $3 / 60$ to no perception of light). ${ }^{15}$

URE was deemed to be present if the presenting VA improved to at least $6 / 18$ with refraction (best correction). ${ }^{7}$ Whenever there were multiple causes, based on the clinical examination and the retinal images, the cause which most likely explained the vision loss in the eye was considered the primary cause. In cases of bilateral surgery where there were different causes of VI in each eye of a participant, the cause that was more easily correctable or treatable to regain vision was considered the primary cause for that participant. For example, if URE was the main cause of VI in one eye and PCO in the other eye, then URE was considered as the main cause and used for analysis. ${ }^{12}{ }^{13}$ VI due to URE or PCO was considered as avoidable. Effective cataract surgical coverage (eCSC) was defined as the number of people with a good outcome after cataract surgery divided by the number with vision-impairing cataract plus those operated for cataract. ${ }^{16}$ To enable comparison with recent studies, the mild VI category (presenting VA worse than 6/12-6/18) as proposed by WHO was also used. ${ }^{17}$

\section{Data management}

Data analysis was conducted using Stata statistical software version 14 (StataCorp LP, TX). ${ }^{18}$ The prevalence of postoperative good visual outcomes was calculated and presented with 95\% CIs. Univariable and multivariable analyses were conducted to explore the factors associated with good outcomes. Multiple logistic regression was done using generalised estimating equation along with robust variance estimation to account for correlation between the two eyes of an individual. In the regression models, 'good outcome' was considered a dependent variable, with covariates being age group, gender, education (no formal education/any education), type of home (free, aided or private), place of surgery (private hospital, government hospital or nongovernment hospital), cost of surgery (free/paid), time from eye surgery (0-5 years, 6-10 years or $>10$ years), diabetes (yes/no), hypertension (yes/no) and mobility score. Eyes offering no visualisation of the lens $(n=3)$ and those with aphakia $(n=39)$ were excluded from this analysis.

\section{RESULTS}

Overall, 1182 participants were examined from 41 homes for the aged in Hyderabad with 703 (59.5\%) having had cataract surgery in at least one eye. The mean age of those who had cataract surgery was 77.5 years (SD: 8.2 years; range: 60-108 years), $470(66.8 \%)$ were women, $389(55.3 \%)$ had independent mobility, $245(34.9 \%)$ needed assistance for mobility and $69(9.8 \%)$ were bedridden; 210 (29.9\%) reported diabetes and 429 (61\%) reported hypertension, $113(16.1 \%)$ reported current/past smoking and 105 (14.9\%) reported current/past alcohol consumption. The prevalence of unilateral cataract surgery was $16.2 \%(95 \% \mathrm{CI}$ 14.1 to $18.4 ; \mathrm{n}=191)$ and bilateral surgery was $43.3 \%(95 \% \mathrm{CI}$ 40.5 to $46.2 ; n=512)$. While unilateral cataract surgery was highest among those aged 70-79 years, bilateral cataract surgery was highest among those aged $\geq 80$ years (table 1 ). The eCSC for persons with VA threshold of $6 / 18$ and $6 / 12$ was $69.0 \%$ and $40.9 \%$, respectively.

\section{Operated eyes}

A total of 1215 eyes of 703 individuals were operated for cataract; 1173 (96.8\%) had intraocular lens (IOLs) implantation, 39 (3.2\%) were aphakic. There was no view of the lens in 3 cases. Of the operated eyes, $527(45.2 \%)$ eyes were operated within the last 5 years, $404(34.6 \%)$ operated $6-10$ years ago and $236(20.2 \%)$ eyes operated more than 10 years ago. A total of $750(64.3 \%)$ surgeries were done in private hospitals compared to 280 $(24.0 \%)$ in non-government hospitals and $137(11.7 \%)$ in government hospitals; 776 (66.5\%) were free surgeries while 319 (33.5\%) were paid surgeries. In all, 30 participants ( $n=48$ eyes) could not 
Table 1 Characteristics of the participants who had undergone cataract surgery in either eye $(n=703)$

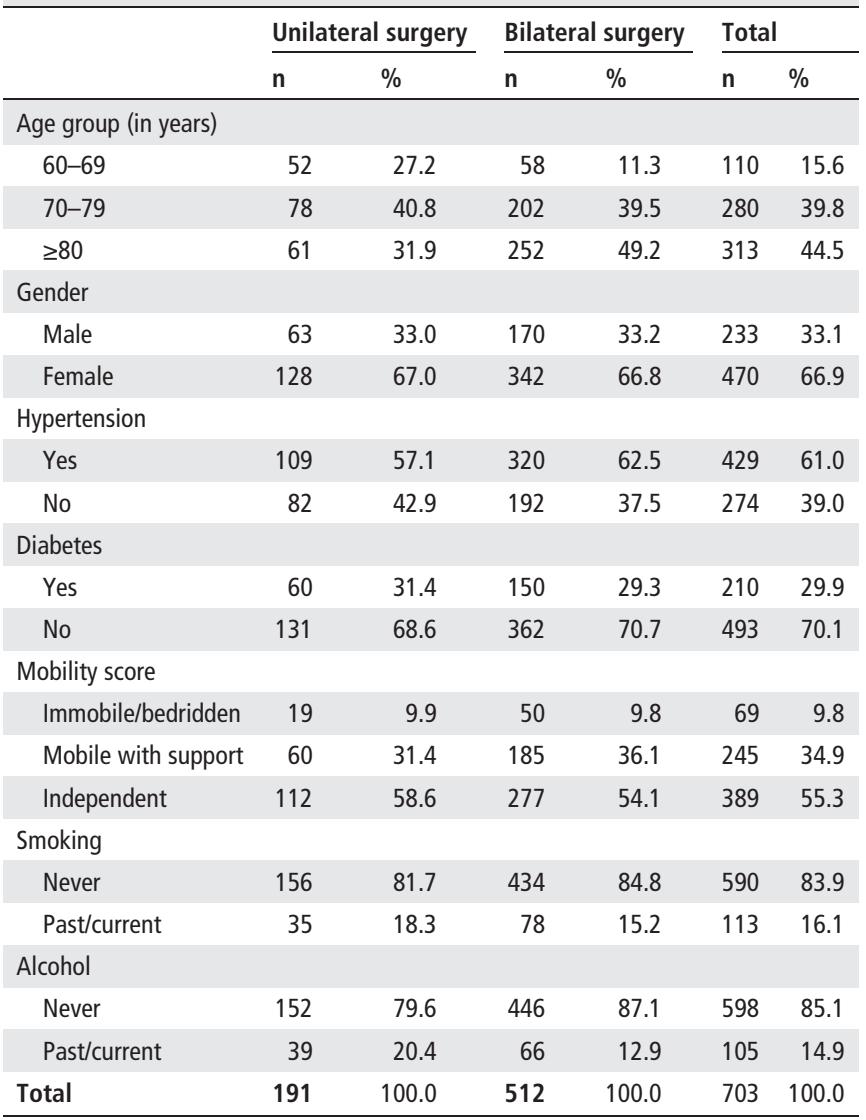

recall the details of the surgery such as where surgery was performed or who paid for surgery or it is free. On applying univariable analysis, good visual outcome (defined by presenting VA better than 6/18) after cataract surgery was associated with pseudophakia, place of surgery and cost of surgery (table 2). The outcomes were better among those with an IOLs (98.3\%) and those operated less than 5 years ago (47.1\%). Those in private clinics (68\%) had better outcomes compared to NGO hospitals (23.8\%) and government hospitals (8.2\%). Paid surgeries had a better outcome than free surgeries $(71.3 \%$ vs $28.7 \% ; \mathrm{p}<0.001)$. The results were similar when definition 2 (presenting VA 6/12 or better) was used except that a shorter time since surgery was associated with good VA after cataract surgery $(\mathrm{p}<0.01)$.

Of the $406 / 1215$ (33.4\%; 95\% CI 30.8 to 36.1 ) eyes that had VI after cataract surgery, 287 (23.6\%; 95\% CI 21.3 to 26.1$)$ eyes had moderate VI, 46 (3.8\%; 95\% CI 2.8 to 5.0$)$ eyes had severe VI and 73 (6\%; $95 \%$ CI 4.7 to 7.5 ) eyes were blind (table 3). PCO $(31.8 \% ; \mathrm{n}=129)$ was the leading cause of VI, followed by URE $(24.1 \% ; n=98)$, posterior segment disease/unexplained vision loss $(10.1 \% ; \mathrm{n}=41)$ and age-related macular degeneration $(8.6 \% ; \mathrm{n}=35)$. In total, $55.9 \%$ of the VI was due to avoidable causes. In addition, mild VI (presenting VA 6/12-6/18) was present in 301/1215 (24.8\%; 95\% CI 22.3 to 27.3$)$ operated eyes of which about $66 \%$ was due to avoidable causes (URE-41.5\% $(\mathrm{n}=125)$ and $\mathrm{PCO}-24.6 \%(\mathrm{n}=74)$.

\section{VI after cataract surgery (persons)}

In total, $95 / 512(18.5 \%, 95 \%$ CI 15.3 to 22.2$)$ people who had VI after bilateral cataract surgery included 78 (15.2\%;
Table 2 Characteristics of the eyes operated for cataract among the elderly residents in homes for the aged $(n=1215)$

\begin{tabular}{|c|c|c|c|c|c|}
\hline & \multirow{2}{*}{$\begin{array}{l}\begin{array}{l}\text { Total } \\
\text { operated } \\
\text { eyes } \\
(n=1215)\end{array} \\
n(\%)\end{array}$} & \multicolumn{2}{|c|}{$\begin{array}{l}\text { Good outcomes } \\
\text { Definition } 1 \\
\text { (presenting visual } \\
\text { acuity } 6 / 18 \text { or } \\
\text { better) }(n=809)\end{array}$} & \multicolumn{2}{|c|}{$\begin{array}{l}\text { Good outcomes } \\
\text { Definition } 2 \\
\text { (presenting visual } \\
\text { acuity } 6 / 12 \text { or } \\
\text { better) }(n=508)\end{array}$} \\
\hline & & $\mathrm{n}(\%)$ & $P$ value & & $P$ value \\
\hline Lens status* & & & $<0.001$ & & $<0.01$ \\
\hline Aphakia & $39(3.2)$ & $14(1.7)$ & & $6(1.2)$ & \\
\hline Pseudophakia & $1173(96.8)$ & 795 (98.3) & & $502(98.8)$ & \\
\hline \multicolumn{6}{|c|}{ Years lapsed after surgery ${ }^{\dagger}$} \\
\hline$<5$ & $527(45.2)$ & $372(47.1)$ & 0.089 & $238(47.8)$ & 0.01 \\
\hline $6-10$ & $404(34.6)$ & $270(34.2)$ & & 179 (35.9) & \\
\hline$>10$ & $236(20.2)$ & $148(18.7)$ & & $81(16.3)$ & \\
\hline \multicolumn{6}{|l|}{ Place of surgery $\dagger_{,} \ddagger$} \\
\hline $\begin{array}{l}\text { Government } \\
\text { hospital }\end{array}$ & $137(11.7)$ & $65(8.2)$ & $<0.001$ & $27(5.5)$ & $<0.001$ \\
\hline $\begin{array}{l}\text { Non- } \\
\text { governmental } \\
\text { organisation } \\
\text { hospital }\end{array}$ & $280(24.0)$ & $188(23.8)$ & & $117(23.9)$ & \\
\hline Private clinic & $750(64.3)$ & $537(68.0)$ & & $345(70.6)$ & \\
\hline Cost of surgeryt, $\ddagger$ & & & $<0.001$ & & $<0.001$ \\
\hline Free surgery & 391 (33.5) & $227(28.7)$ & & $120(24.1)$ & \\
\hline Paid surgery & $776(66.5)$ & $563(71.3)$ & & $378(75.9)$ & \\
\hline
\end{tabular}

*No view of the lens in three eyes.

tData not available in 48 eyes.

‡Data not available in 28 eyes.

Table 3 Prevalence of visual impairment (VI) following cataract surgery among the elderly in residential care

\begin{tabular}{|c|c|c|c|c|}
\hline & \multicolumn{2}{|c|}{ Eyes $(n=1215)$} & \multicolumn{2}{|c|}{ Persons $(n=512)$} \\
\hline & $\mathrm{n}$ & $\begin{array}{l}\text { Prevalence } \\
(95 \% \mathrm{Cl})\end{array}$ & $\mathrm{n}$ & $\begin{array}{l}\text { Prevalence } \\
(95 \% \mathrm{Cl})\end{array}$ \\
\hline $\begin{array}{l}\text { Moderate VI (presenting } \\
\text { visual acuity worse than } \\
6 / 18-6 / 60)\end{array}$ & 287 & 23.6 (21.3 to 26.1$)$ & 78 & 15.2 (12.2 to 18.6$)$ \\
\hline $\begin{array}{l}\text { Severe VI (presenting visual } \\
\text { acuity worse than } 6 / 60-3 / 60 \text { ) }\end{array}$ & 46 & 3.8 (2.8 to 5.0$)$ & 11 & 2.1 (1.1 to 3.8$)$ \\
\hline $\begin{array}{l}\text { Blindness (presenting visual } \\
\text { acuity worse than } 3 / 60 \text { to no } \\
\text { light perception) }\end{array}$ & 73 & $6.0(4.7$ to 7.5$)$ & 6 & $1.2(0.4-2.5)$ \\
\hline All VI & 406 & 33.4 (30.8 to 36.1$)$ & 95 & 18.5 (15.3 to 22.2$)$ \\
\hline
\end{tabular}

95\% CI 12.2 to 18.6$)$ participants with moderate VI, 11 with severe VI $(2.1 \%$; $95 \%$ CI 1.1 to 3.8$)$ and $6(1.2 \%$; $95 \%$ CI 0.4 to 2.5$)$ with blindness. PCO $(33.7 \%$; $=32)$ and URE $(33.7 \% ; n=32)$ were the leading causes of VI, followed by glaucoma $(7.4 \% ; \mathrm{n}=7)$, age-related macular degeneration $(6.3 \% ; n=6)$ and optic atrophy $(6.3 \% ; n=6)$ (table 4$)$. In total, $67.4 \%$ of the VI was due to avoidable causes. A large proportion of blindness was due to unavoidable causes, whereas a large portion of moderate and severe VI was due to avoidable causes. In addition, mild VI (presenting VA 6/12-6/18) was present in 130/512 (25.4\%; 95\% CI 21.7 to 29.4) participants who had bilateral cataract surgery of which $65.3 \%$ were due to avoidable causes (URE-46.1\% ( $\mathrm{n}=60)$ and $\mathrm{PCO}-19.2 \%(\mathrm{n}=25))$. 
Table 4 The cause of vision impairment following cataract surgery in the elderly in residential care

\begin{tabular}{|c|c|c|c|c|}
\hline & $\begin{array}{l}\text { Moderate vision impairment } \\
\text { (presenting visual acuity worse } \\
\text { than } 6 / 18-6 / 60 \text { in the } \\
\text { better-seeing eye) }(\%)\end{array}$ & $\begin{array}{l}\text { Severe vision impairment } \\
\text { (presenting visual acuity } \\
\text { worse than } 6 / 60-3 / 60 \text { in the } \\
\text { better-seeing eye) }(\%)\end{array}$ & $\begin{array}{l}\text { Blindness (presenting visual } \\
\text { acuity worse than } 3 / 60 \text { to no } \\
\text { light perception in the } \\
\text { better-seeing eye) (\%) }\end{array}$ & $\begin{array}{l}\text { Total vision impairment } \\
\text { (presenting visual acuity } \\
\text { worse than } 6 / 18 \text { to no light } \\
\text { perception in the } \\
\text { better-seeing eye) (\%) }\end{array}$ \\
\hline \multicolumn{5}{|l|}{ VI causes-eyes $(n=1215)$} \\
\hline & $\mathrm{n}=287$ & $n=46$ & $\mathrm{n}=73$ & $\mathrm{n}=406$ \\
\hline Posterior capsule opacification (PCO) & 35.9 & 28.3 & 17.8 & 31.8 \\
\hline Uncorrected refractive error (URE) & 32.1 & 4.3 & 5.5 & 24.1 \\
\hline Other posterior segment disorders & 8.4 & 13.0 & 15.1 & 10.1 \\
\hline Age-related macular degeneration & 4.9 & 13.0 & 20.5 & 8.6 \\
\hline Glaucoma & 6.3 & 8.7 & 13.7 & 7.9 \\
\hline Optic atrophy & 5.2 & 13.0 & 8.2 & 6.7 \\
\hline Other causes & 3.5 & 6.5 & 5.5 & 4.2 \\
\hline Corneal scar & 1.7 & 4.3 & 11.0 & 3.7 \\
\hline Diabetic retinopathy & 1.0 & 4.3 & 1.4 & 1.5 \\
\hline \multirow[t]{2}{*}{ Chorioretinal scars } & 1.0 & 4.3 & 1.4 & 1.5 \\
\hline & 100.0 & 100.0 & 100.0 & 100.0 \\
\hline \multicolumn{5}{|l|}{ Causes_-persons $(\mathrm{n}=512)$} \\
\hline & $\mathrm{n}=78$ & $n=11$ & $\mathrm{n}=6$ & $\mathrm{n}=95$ \\
\hline URE & 38.5 & 18.2 & 0.0 & 33.7 \\
\hline PCO & 37.2 & 18.2 & 16.7 & 33.7 \\
\hline Glaucoma & 7.7 & 0.0 & 16.7 & 7.4 \\
\hline Age-related macular degeneration & 3.8 & 18.2 & 16.7 & 6.3 \\
\hline Optic atrophy & 5.1 & 9.1 & 16.7 & 6.3 \\
\hline Other posterior segment disorders & 3.8 & 9.1 & 16.7 & 5.3 \\
\hline Corneal scar & 1.3 & 9.1 & 16.7 & 3.2 \\
\hline Other causes & 1.3 & 9.1 & 0.0 & 2.1 \\
\hline Diabetic retinopathy & 1.3 & 0.0 & 0.0 & 1.1 \\
\hline \multirow[t]{2}{*}{ Chorioretinal scars } & 0.0 & 9.1 & 0.0 & 1.1 \\
\hline & 100.0 & 100.0 & 100.0 & 100.0 \\
\hline
\end{tabular}

Among the participants who had bilateral cataract surgery and had VI postsurgery, URE was the leading cause of VI in the age group of 60-69 years and 70-79 years, whereas PCO was the leading cause in participants aged $\geq 80$ years $(p<0.01)$. URE was the leading cause among those without any education and PCO was the leading cause among those who were educated $(p<0.01)$. While the causes of VI did not vary with diabetes status $(p=0.17)$, those with self-reported hypertension had PCO as the leading cause of VI compared to URE among those without hypertension $(\mathrm{p}<0.01)$. PCO was the leading cause of VI $(68.8 \%)$ among the participants who were immobile/bedridden, while URE was the leading cause in those who had mobility with support or independently mobile $(\mathrm{p}<0.05)$. The causes of VI did not vary with gender $(\mathrm{p}=0.29)$.

The association of causes of VI after cataract surgery with place of surgery, paid versus free surgery and duration in years since surgery was assessed. Posterior segment disease was the leading cause of VI after cataract surgery though its proportion varied with place of surgery; it was not statistically significant $(\mathrm{p}=0.30)$. Posterior segment disease $(38.4 \%)$, URE $(28.7 \%)$ and PCO (21.9\%) were the causes among free surgeries compared to posterior segment disease (36.1\%), URE (24.7\%) and PCO (30.5\%) among paid surgeries $(p<0.01)$. The causes of VI did not vary with duration since surgery $(\mathrm{p}=0.16)$.
Risk factors related to visual outcomes after cataract surgery On applying multiple logistic regression analysis, those $\geq 80$ years had substantially lower odds of good outcomes (definition 1), though this was not statistically significant (OR: $0.68 ; 95 \% \mathrm{CI}$ 0.44 to 1.04$)$. Those with self-reported hypertension were more likely to have good visual outcomes (OR: 1.45; 95\% CI 1.10 to 1.91). Compared to those who were bedridden, the odds of good outcomes were higher for those who needed assistance for mobility (OR: $1.69 ; 95 \%$ CI 1.07 to 2.67 ) and also for those who were independently mobile (OR: 2.34 ; 95\% CI 1.50 to 3.66). Having been operated on in a NGO-run hospital (OR: 1.91; 95\% CI 1.19 to 3.08 ) and undergoing paid surgery (OR: 1.64 ; $95 \%$ CI 1.09 to 2.50) had higher odds for good outcomes. Length of time after surgery and self-report of diabetes was not associated with outcomes (table 5). Similar associations were found when definition 2 (presenting VA $6 / 12$ or better) was used as a good outcome except for a positive association between self-report of diabetes and good outcomes.

\section{DISCUSSION}

One-third of the eyes of elderly residents living in homes for the aged in Hyderabad, India, had VI (defined as presenting VA worse than 6/18) after cataract surgery. This increased to $58.2 \%$ when VI was defined as VA worse than $6 / 12$. Nearly $20 \%$ of those who had undergone bilateral cataract surgery had bilateral VI defined 
Table 5 Multivariable logistic regression analysis (generalised estimating equation) showing the factors associated with good visual outcomes after cataract surgery with intraocular lens implantation

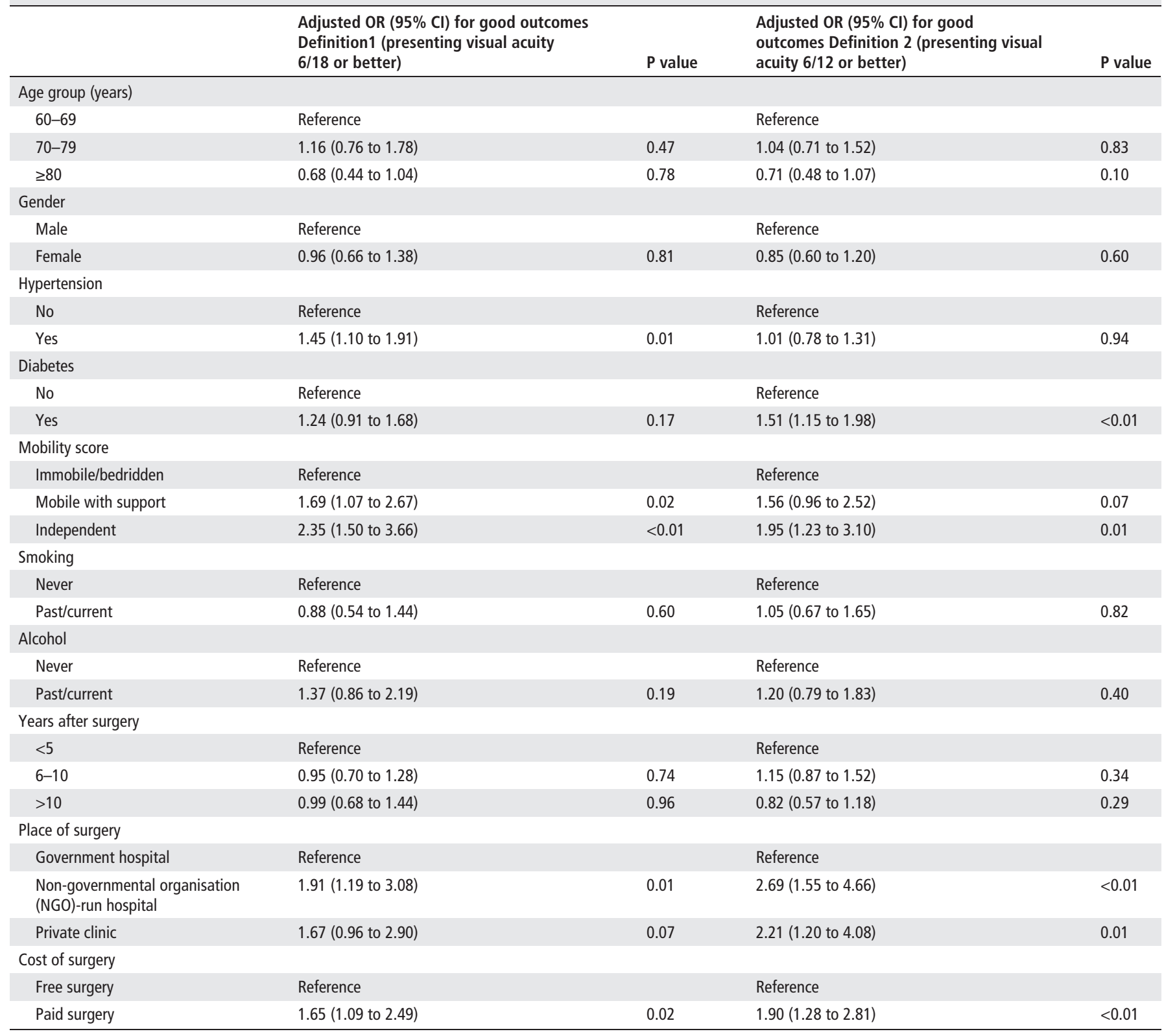

as presenting vision worse than $6 / 18$ in both eyes. ${ }^{19}$ A large proportion of VI was moderate with only a small proportion having severe VI or blindness. PCO was the leading cause of VI, a unique finding though earlier studies also had reported it as one cause of VI, but not the number one cause. ${ }^{20}$ The APEDS reported that half of the operated eyes in Hyderabad in 1999 had VI after cataract surgery. ${ }^{11}$ In 2009 , another study that included urban areas of Andhra Pradesh reported better outcomes compared to the 1999 study, with $22.4 \%$ of operated eyes having poor outcomes after cataract surgery, similar to the findings of the present study among elderly in residential care. ${ }^{8}$

Several population-based studies from the rest of India have reported on visual outcomes after cataract surgery, and ${ }^{7} 8$ 20-22 URE is the leading cause for poor outcomes. ${ }^{7-9} 1120$ We confirm the importance of UREs, but in this study, PCO was the leading cause. The younger participants in earlier population-based studies compared to our study may explain to some extent the higher
PCO rates in our study. We also actively assessed for PCO using a standardised grading system. Others may have missed this as a cause of VI due to the examination protocols used.

The higher prevalence of cataract surgery in older age groups and among women in our study is similar to that in earlier studies from this region. ${ }^{911}$ We found a very high prevalence of bilateral cataract surgery in our study population, indicating that cataract surgical services are both available as well as accessed by the elderly in this urban region. As in previous studies, we found poorer visual outcomes in older age groups. ${ }^{7} 811$ This is likely due to ocular co-morbidities that are more common in older age groups as well as time since surgery resulting in a lower likelihood of having appropriate spectacles and a higher likelihood of having PCO. We also found that the odds were higher for good outcomes among those with self-reported hypertension. As our definition of hypertension relied on self-report, it is probable that this association is due to better access to 
healthcare and possibly increased utilisation of health facilities by those who reported hypertension. However, we did not find a significant association between self-reported diabetes and visual outcomes (6/18 definition) following cataract surgery though a positive association was found for definition $2(6 / 12$ definition). Those with diabetes who end up in homes for the aged may be survivors and healthier, and/or may have been undergoing regular health check-up, which helped detection and management of ocular conditions resulting in better outcomes.

Eyes operated in hospitals run by NGOs that provide both paying and non-paying surgeries had better visual outcomes. The possible reason for better outcomes in NGO or private facilities is the greater use of biometry and greater access to IOLs with a wide range of powers for implantation. Furthermore, those who paid for surgery had higher odds of good outcomes. This is probably indicative of the quality and type of surgery with better IOLs and more attention to refraction and PCO after surgery for patients who pay for surgical services. ${ }^{23}$ Also, those who paid for surgery may have been operated by more experienced surgeons, which may have resulted in better outcomes.

Overall, our findings indicate that people seek and receive cataract surgery but miss out on regular follow-up consultations, which are essential to maintain clear vision. Our study population is especially vulnerable as they live in residential care and lack independence. Typically, NGOs reach out to provide cataract surgery to the elderly, often without a user fee. They provide transport facilities and other support for surgery. However, continuity of care is lacking after cataract surgery. Service providers need to reach out to this population to ensure proper follow-up care. While refractive errors can be corrected in homes for the aged, those who require additional treatment will need to be referred for care. Portable neodymium-doped yttrium aluminium garnet (Nd:YAG) lasers have been used in the past for performing iridotomy and could similarly be considered for capsulotomy. ${ }^{24}$ Portable retinal lasers are used to treat retinopathy of prematurity in infants. The use of such technologies could allow for a more streamlined provision of care to those who are immobile, bedridden or have limited mobility. Though the number of people who can benefit from portable Nd:YAG laser may not be high, with an ageing population and ever-increasing number of cataract surgeries over the years, portable technology usage could be beneficial.

Our study focused on the elderly population in residential care in Hyderabad; hence, results are not generalisable to other populations. The primary limitations of our study are limited information on the details of the surgeries provided. Residents did not have their surgical records and were operated at many locations, so it was not possible to review surgical records. Furthermore, the diagnosis of posterior segment conditions was performed using images taken through undilated pupils. While we were able to get good quality images in most cases, the details were not clear in a few cases where there were media opacities, such as a dense PCO. We may have underestimated the importance of posterior segment pathologies. PCO was also assessed without pupillary dilatation, which could have led to an underestimation of PCO. Also, our study sample had a higher representation of women, possibly due to a longer life expectancy among women.

In conclusion, homes for the aged are relatively new in India, but the number residing in them is rapidly rising. ${ }^{25} \mathrm{~A}$ large proportion of residents had poor outcomes after cataract surgery that could readily be addressed by simple interventions. A strategic framework for healthcare including eye care would provide surveillance of vision status and open avenues to routinely render appropriate follow-up care for all those who undergo cataract surgery. The elderly in residential care would then be assured of lifelong good eye health.

\section{Author affiliations}

${ }^{1}$ Allen Foster Community Eye Health Research Centre, Gullapalli Pratibha Rao International Centre for Advancement of Rural Eye care, L V Prasad Eye Institute, Hyderabad, India

${ }^{2}$ Brien Holden Institute of Optometry and Vision Science, L V Prasad Eye Institute, Hyderabad, India

${ }^{3}$ Department of Biotechnology / Wellcome Trust India Alliance, L V Prasad Eye Institute, Hyderabad, India

${ }^{4}$ School of Optometry and Vision Science, University of New South Wales, Sydney, Australia

${ }^{5}$ Massachusetts Eye and Ear, Harvard Medical School Department of Ophthalmology, Boston, United States of America

${ }^{6}$ Cataract and Refractive Services, L V Prasad Eye Institute, Hyderabad, India

Correction notice This paper has been amended since it was published online. The first author's name was incorrectly transposed.

Acknowledgements The authors thank the study participants for their committed contribution, Mr Shashank Yellapragada for his assistance in data collection, Ms Mun Rajya Lakshmi for her support in data management and Prof. Jill E. Keeffe (L V Prasad Eye Institute) for her inputs on earlier versions of the manuscript. The authors thank Ms Neha Hassija and Dr Shobha Mocherla for their language inputs on earlier versions of the manuscript.

Contributors SM conceived the idea, designed and conducted the study, analysed the data and wrote the manuscript. NRB, RC, TRK, SBM and MB are involved in data collection. RY assisted in data management. RCK and DF reviewed the earlier version of the manuscripts and provide the intellectual inputs.

Funding This work was supported by Wellcome Trust/DBT India Alliance Fellowship (IA/CPHE/14/1/501506) awarded to Dr Srinivas Marmamula and Hyderabad Eye Research Foundation (HERF), India.

Competing interests None declared.

Provenance and peer review Not commissioned; externally peer reviewed. Data availability statement No data are available.

Open access This is an open access article distributed in accordance with the Creative Commons Attribution 4.0 Unported (CC BY 4.0) license, which permits others to copy, redistribute, remix, transform and build upon this work for any purpose, provided the original work is properly cited, a link to the licence is given, and indication of whether changes were made. See: https://creativecommons.org/licenses/ by/4.0/.

\section{ORCID iDs}

Srinivas Marmamula http://orcid.org/0000-0003-1716-9809

Jagadesh C Reddy http://orcid.org/0000-0001-9836-0597

Rohit C Khanna http://orcid.org/0000-0002-8698-5562

\section{REFERENCES}

1 Flaxman SR, Bourne RRA, Resnikoff S, et al. Global causes of blindness and distance vision impairment 1990-2020: a systematic review and meta-analysis. Lancet Glob Health 2017;5:e1221-e1234.

2 Davis G. The evolution of cataract surgery. Mo Med 2016;113:58-62.

3 Finger RP, Kupitz DG, Fenwick E, et al. The impact of successful cataract surgery on quality of life, household income and social status in South India. PLOS One 2012;7: e44268

4 Lamoureux EL, Fenwick E, Pesudovs $\mathrm{K}$, et al. The impact of cataract surgery on quality of life. Curr Opin Ophthalmol 2011;22:19-27.

5 Lansingh VC, Carter MJ, Martens M. Global cost-effectiveness of cataract surgery. Ophthalmology 2007:1670-8.

6 Khanna R, Pujari S, Sangwan V. Cataract surgery in developing countries. Curr Opin Ophthalmol 2011;22:10-14.

7 Khanna RC, Pallerla SR, Eeda SS, et al. Population based outcomes of cataract surgery in three tribal areas of Andhra Pradesh, India: risk factors for poor outcomes. PLoS One 2012; 7:e35701.

8 Marmamula S, Khanna RC, Shekhar K, et al. Outcomes of cataract surgery in urban and rural population in the South Indian State of Andhra Pradesh: Rapid Assessment of Visual Impairment (RAVI) project. PLoS One 2016;11:e0167708. 
9 Dandona L, Dandona R, Anand R, et al. Outcome and number of cataract surgeries in India: Policy issues for blindness control. Clin Exp Ophthalmol 2003;31:23-31.

10 Bachani D, Gupta SK, Murthy GV, et al. Visual outcomes after cataract surgery and cataract surgical coverage in India. Int Ophthalmol 1999;23:49-56.

11 Dandona L, Dandona R, Naduvilath TJ, et al. Population-based assessment of the outcome of cataract surgery in an urban population in Southern India. Am J Ophthalmol 1999;127:650-8.

12 Marmamula S, Barrenkala NR, Challa R, et al. Hyderabad Ocular Morbidity in Elderly Study (HOMES) - rationale, study design and methodology. Ophthalmic Epidemiol 2020;27:83-92.

13 Marmamula S, Barrenakala NR, Challa R, et al. Prevalence and risk factors for visual impairment among elderly residents in 'homes for the aged' in India: the Hyderabad Ocular Morbidity in Elderly Study (HOMES). Br J Ophthalmol 2020;bjophthalmol-2019315678.

14 Marmamula S, Barrenkala NR, Challa R, et al. Uncorrected refractive errors for distance among the residents in 'homes for the aged' in South India - the Hyderabad Ocular Morbidity in Elderly Study (HOMES). Ophthalmic Physiol Opt 2020;40:343-9.

15 Vashist P, Senjam SS, Gupta V, et al. Definition of blindness under national programme for control of blindness: do we need to revise it? Indian J Ophthalmol 2017:65:92-6.

16 Ramke J, Gilbert CE, Lee AC, et al. Effective cataract surgical coverage: an indicator for measuring quality-of-care in the context of universal health coverage. PLoS One 2017:12:e0172342.
17 Bourne RRA, Flaxman SR, Braithwaite T, et al. Magnitude, temporal trends, and projections of the global prevalence of blindness and distance and near vision impairment: a systematic review and meta-analysis. Lancet Glob Health 2017;5:e888e897.

18 StataCorp. Stata statistical software: release 14. College Station, TX: StataCorp LP., 2014.

19 WHO. Informal consultation on analysis of blindness prevention outcomes. WHO/PBL/ 9868. Geneva: World Health Organization, 1998.

20 Murthy GV, Vashist P, John N, et al. Prevalence and vision-related outcomes of cataract surgery in Gujarat, India. Ophthalmic Epidemiol 2009;16:400-9.

21 Paul P, Kuriakose T, John J, et al. Prevalence and visual outcomes of cataract surgery in rural South India: a cross-sectional study. Ophthalmic Epidemiol 2016:23:309-15.

22 Chandrashekhar TS, Bhat HV, Pai RP, et al. Coverage, utilization and barriers to cataract surgical services in rural South India: results from a population-based study. Public Health 2007;121:130-6.

23 Sinha R, Shekhar H, Sharma N, et al. Posterior capsular opacification: a review. Indian J Ophthalmol 2013;61:371-6.

24 Robin AL, Arkell S, Gilbert SM, et al. Q-switched neodymium-YAG laser iridotomy. A field trial with a portable laser system. Arch Ophthalmol 1986;104:526-30.

25 UNPF. Caring for our elders: early responses - India ageing report - 2017. New Delhi, India: United Nations Population Fund, 2017. 